\title{
Warm Climate Production Guidelines for Japanese Hydrangeas ${ }^{1}$
}

\section{Dr. Rick Shoellhorn and Alexis A. Richardson ${ }^{2}$}

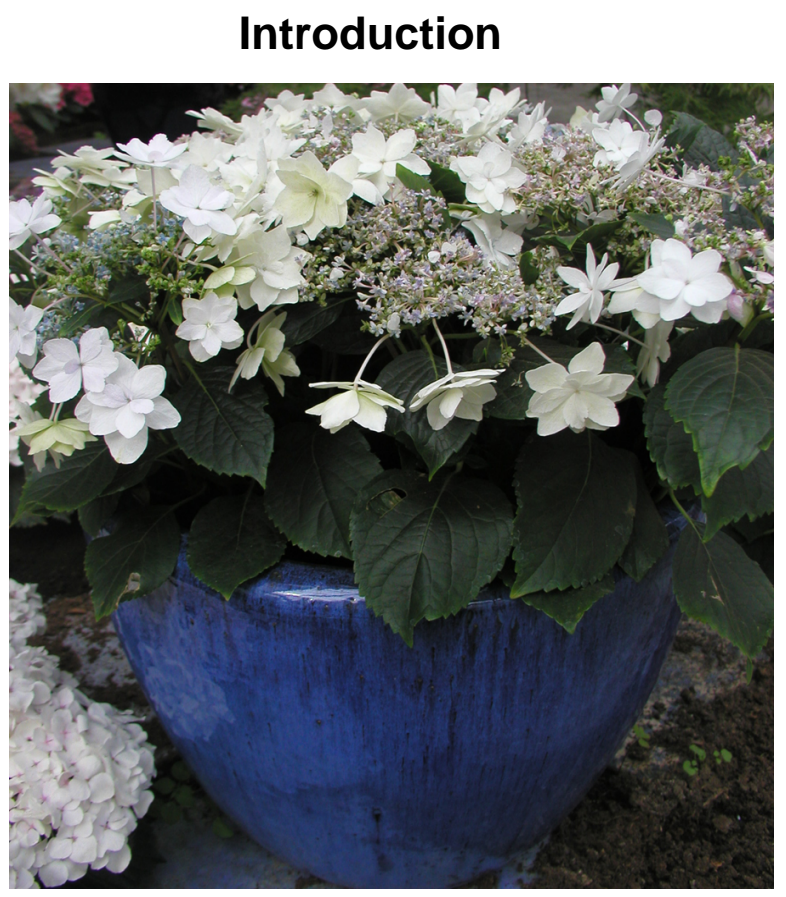

Figure 1. Lace cap hydrangea.

Lace cap hydrangeas can be a great way for Florida growers to produce something that defines their niche as specialty growers and offers a high profit plant for spring and holiday sales.
We always think we will have to hunt to find great new plants, but occasionally they show up where we least expect them. I went to the grocery store to buy flowers and discovered a series of lace cap hydrangeas with a flower form totally different from any I had seen before. I have since seen these hybrids in all shades of white, blue, mauve and pink.

I made a similar discovery this past year during the holiday season while I was searching for something different from poinsettias to put around my tree. I was looking for a break from tradition when I stumbled into my local grocery store and discovered some of the new Japanese hydrangea hybrids on display.

In both these cases, the hydrangeas I found came from a nursery called Hana Bay Flowers marketed through Bay City Flower Company in Half Moon Bay California. Bay City offers both finished and pre-finished hydrangeas.

These new Japanese releases will change the way you view this crop, because they do not look like the old-fashioned pompom forms. The foliage is similar to the newer lace cap hybrids, and the star-shaped flower forms are unique. The effect is more graceful

1. This document is ENH910, one of a series of the Environmental Horticulture Department, Florida Cooperative Extension Service, Institute of Food and Agricultural Sciences, University of Florida. Original publication date February 5, 2005. Please visit the EDIS web site at http://edis.ifas.ufl.edu.

2. Rick Shoellhorn, associate professor, commercial floriculure specialist; Alexis A. Richardson, contributing writer; Environmental Horticulture Department, Institute of Food and Agricultural Sciences, University of Florida, Gainesville FL 32611.

The Institute of Food and Agricultural Sciences (IFAS) is an Equal Opportunity Institution authorized to provide research, educational information and other services only to individuals and institutions that function with non-discrimination with respect to race, creed, color, religion, age, disability, sex, sexual orientation, marital status, national origin, political opinions or affiliations. U.S. Department of Agriculture, Cooperative Extension Service, University of Florida, IFAS, Florida A. \& M. University Cooperative Extension Program, and Boards of County Commissioners Cooperating. Larry Arrington, Dean 
and more of a novelty than the standard flowering forms. There is also a lot of color blending in the new cultivars with more red and red tones blended into the traditional white, pink and blue we think of when we think of the florist's hydrangea. The reason that I wanted to raise awareness of these hybrids is twofold. First, as with a lot of flowering potted plants, hydrangeas have gotten locked into the Easter/Mother's Day market when in fact they deserve attention throughout the year. Secondly, the new cultivars offer retailers and wholesalers a great opportunity in novelty flowering crops, with a higher profit margin.

I met Tim Wood of Spring Meadow Nursery in Tennessee recently and we looked over his catalog of hydrangea cultivars, which are predominantly for the landscape industry. The selection of new forms is amazing. Tim had a short list of these new varieties for growers to experiment with that included Hydrangea macrophylla and Hydrangea serrata cultivars. While some taxonomists merge these two species, they can still be found separated in the trade, so don't be surprised to see them listed separately in catalogs. Also, the original Japanese names are often converted into American cultivar names in the US, so you may find some cultivars offered under different names. This practice is common when new crops enter our market and are released.

The American market for hydrangea cultivars is currently rather limited, but the introductions from the suppliers listed in this publication are rapidly widening the types and colors available.

There are around six major genera of Hydrangeas used in the United States. Some are suited for pot culture and others are not. Many companies besides those listed here supply finished and pre-finished Hydrangeas.

For flowering potted plant production, most growers will find that it is easier to bring in 4-inch pre-finished material and force it in a 6 -inch pot. The process is about 14 weeks long under normal greenhouse conditions. For the landscape industry, rooted liners are usually ready for sale in 1-2 years.

Here is a short description of some of the cultivars available from Spring Meadows:

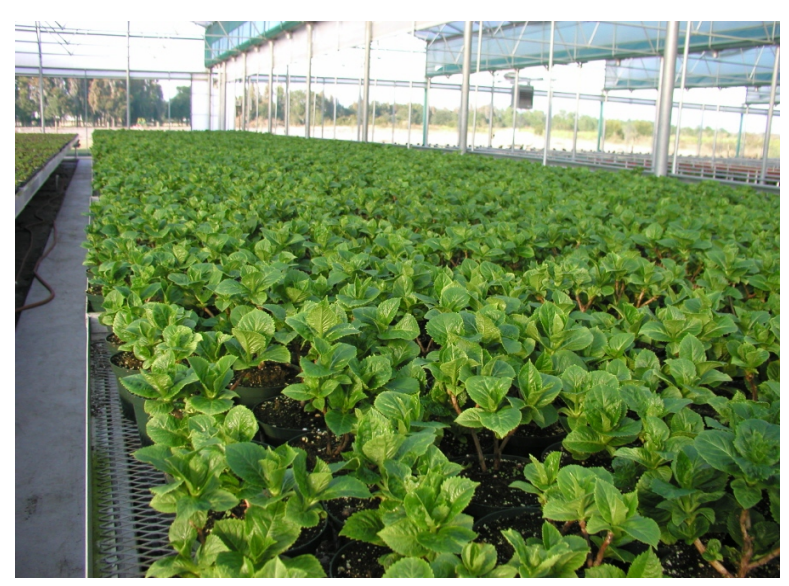

Figure 2. Potted plant production.

\section{Hydrangea serrata cultivars}

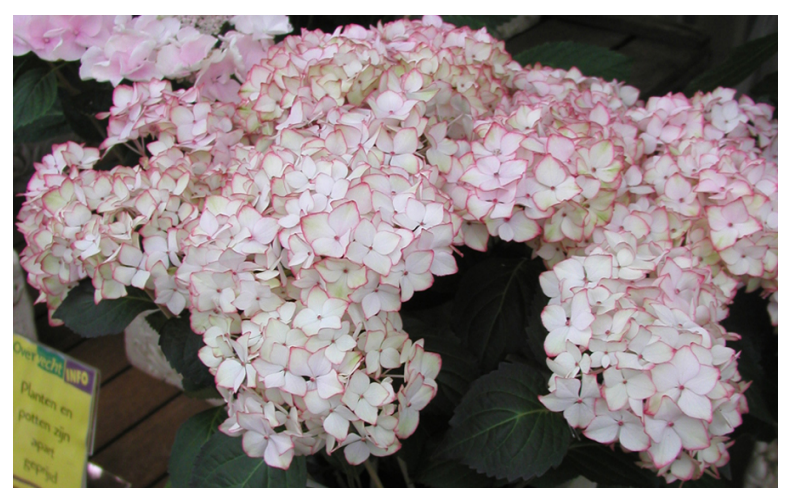

Figure 3. 'Kiyosumi' hydrangea.

'Kiyosumi' - A white flowered, lace cap form with some red around the margins of the florets. The new vegetative growth has a deep red flush, adding another layer to the interest of the plant.

'Midoriboshi-Temari' - This is a pink lace cap form, but the outer double florets have very long pedicels so that they hang elegantly downwards. This is the growth form I find so interesting and distinctively different from the Hydrangeas we have become accustomed to.

'Miyama yea Muraski' - This plant has double violet to pink florets on bright green foliage. It blends the colors we are used to in Hydrangeas and has an excellent form as well.

'Shirofuji' - Double white masses of florets cover the plants. A very nice, low mounding habit when planted in the landscape. 


\section{Hydrangea macrophylla cultivars}

'Izu No Hana' - A lace cap type with double pink sterile florets and rounded petals surrounding the central lace cap. It is hard not think of fireworks when you see this plant because the florets point outward and create the illusion of an expanding flower mass.

'Jogasaki' - This cultivar is similar to 'Izu No Hana,' but its color is a bit more silvery, and the florets have slightly fewer petals, between 8 and 11 per floret. Flowers face up a bit more and create a different effect than that of 'Izu No Hana.'

\section{Both Hydrangea macrophylla and $H$. serrata} offer strong holiday sales and spring interest. Hydrangea macrophylla (Figure 4) is the more common form grown in the United States.

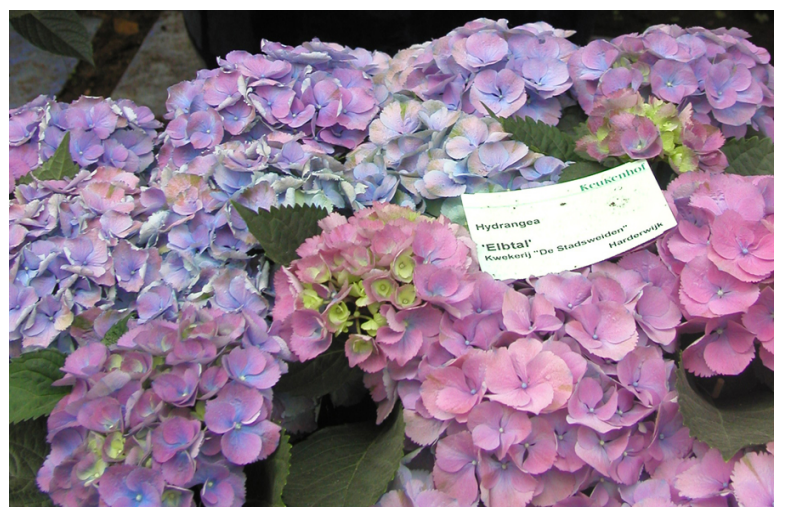

Figure 4. Hydrangea macrophylla.

\section{Commercial Production Guidelines for Pre-Finished Hydrangea}

Hydrangea blooms are formed on the previous year's growth, so when you receive pre-finished liners the flowers are already in place in the dormant buds. The grower's job is to control vegetative growth and provide the conditions that allow for the best flower development possible. This means cool production conditions, bright light levels, a complete fertilizer program, and finishing with cool temperatures to intensify color. Hydrangeas can lose buds if the plants are drought stressed, exposed to ethylene or exhaust fumes, and if temperatures are raised too much during the growing season.

As the average grower gets in a 3- to 5-inch pre-finished plant and bumps it up into a 6-inch or larger finished container, there are a couple of things to keep in mind.

Roots - A good root system is vital. Without one, all the luck in the world will not give you satisfied customers. The way to encourage strong roots is to keep the soil slightly warm $\left(60-65^{\circ} \mathrm{F}\right)$ while keeping the air temperature cooler at around $55^{\circ} \mathrm{F}$. This encourages a shift from shoot production to root production and gives you a stronger root system. You'll want to give newly arrived pre-finished materials a week or two to recover from shipping stress and strengthen their root systems before transplanting, so plan for this time when scheduling.

The major problems growers face with hydrangea crops are poor root systems on the liners, which lead to root problems later in production, and over-watering of the newly planted liners. Use a broad spectrum fungicide at planting and hold off on watering until dormant growth begins emerging and new growth resumes.

Fertilization - The type of fertilizer needed relates to the flower color desired, but in general 150 ppm nitrogen is usually sufficient. Terminate fertilizer when flower buds begin to show color. Fertilizer termination increases the post-harvest life of the flowers.

Watering - Normal production irrigation is fine. Never let plants wilt because they will lose lower leaves and lose overall quality.

Media - You need to know what color you are trying to produce before selecting a medium. A medium with a starter charge may strongly affect final color of the crop, so start planning early. While all commercial peat lite media work fine, optimum $\mathrm{pH}$ depends on the color of flower you are working toward.

Production Temperatures - Hydrangea is a model crop for controlling with temperature. Development (flower and foliage) moves faster at higher temperatures. Temperatures of $55-60^{\circ} \mathrm{F}$ at night and $65-75^{\circ} \mathrm{F}$ in the day are adequate. Temperatures much higher than this usually lead to plants of lower quality. Cooler temperatures will also give deeper color to the blooms. 
Light level - In general, plants do well with good light (5,000+ foot candles), low light levels result in weaker stems, and too high a level of light will cause leaves to yellow.

Propagation - Hydrangeas root easily, but it takes a full year to develop a strong liner for pre-finished use. Semi-hardwood to softwood cuttings are used for developing liners. The optimal age for cuttings depends on the species grown.

Crop timing - Generally, forced hydrangeas as a pre-finished crop take 11 to 14 weeks. There is a lot of variability between the different cultivars.

Growth regulators - PGRs should be applied when there are 3-5 sets of unfolding leaves. Daminozide has been the traditional PGR of choice, and rates range between $2500-5000 \mathrm{ppm}$. Later in the crop, stem elongation can become a problem. In these cases, do not apply growth regulators after flower buds are visible, or you may reduce inflorescence stem length and get a clubby shape on the finished plant. Sprays late in production can cause the flower to fail to elongate, so in most cases weak drenches are best. They will provide more control without affecting flowering. Extremely strong cultivars may need repeated applications. Paclobutrazol can also be used as a drench, but there isn't a lot of information out on rates. Start at 0.5-1 ppm and repeat as needed.

Flowering - When plants reach flowering size and buds first begin to show color, drop temperatures to $55^{\circ} \mathrm{F}$ at night and $65^{\circ} \mathrm{F}$ in the day to increase the coloration of the flowers. In general, first color is about 2-3 weeks before sale.

Controlling flower color - Historically, blue flowers formed in the presence of aluminum, and pink flowers formed in the absence of the element. Breeding efforts have moved Hydrangeas into more color flexible forms and so all shades between pink and purple are now available from mauve to purple to deep reds. Creative growers may want to experiment with applications of aluminum sulfate to see what changes in color this brings out. For blue colors, a more acidic $\mathrm{pH}$ (5.2-5.5) is needed. Applications of aluminum sulfate will both provide aluminum and lower $\mathrm{pH}$. For pink colors, raise $\mathrm{pH}$ above 5.6 and use high phosphate fertilizers as phosphate competes with aluminum and reduces uptake.

Colors and forms are varied, but all Hydrangea serrata hybrids offer a distinguished look and graceful flowers.

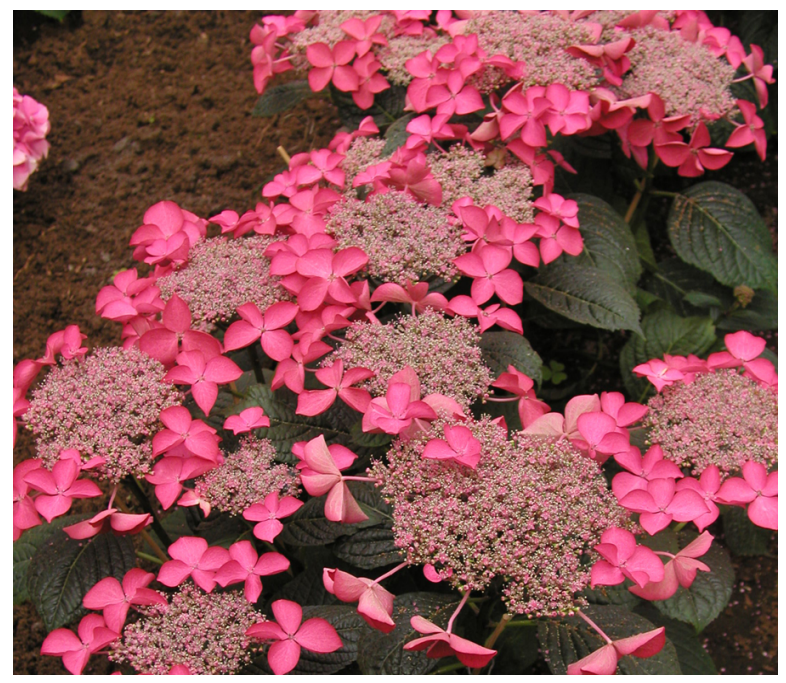

Figure 5. 'Midoriboshi-Temari' hydrangea.

\section{Commercial Sources for Hydrangeas}

Tim Wood, Spring Meadow Nursery 12601 120th Ave., Grand Haven, MI 49417 Phone 616-846-4729 ext. 17; fax 616-846-0619 Website: http://www.springmeadownursery.com

Doug Bailey's articles on Hydrangea production: http://www.ces.ncsu.edu/depts/hort/floriculture/hils/ hil524.html (Dr. Bailey has also published a grower's handbook on Hydrangea production, which is available at most bookstores)

Mark Holcomb's coverage of different species commonly used in the landscape: http://www.utextension.utk.edu/hbin/ Hydrangea\%20prod.pdf

Bay City Flower Co. P.O. Box 186, Half Moon Bay, CA 94019 Phone: (650) 726-5535 